\title{
DESIGN OF DYNAMIC STRUCTURAL MODELS OF INFORMATION MANAGEMENT SYSTEM OF MOVING OBJECTS
}

\author{
Maksym Korobchynskyi ${ }^{1}$, Oleg Mashkov ${ }^{2}$ \\ ${ }^{1}$ Space-air society of Ukraine, ${ }^{2}$ State Ecological Academy for postgraduate education and management
}

Abstract. In the following work the authors attempt to find the best way to design a dynamic structural model of information management system of moving objects. This structural model allows organizing various management systems of moving objects, considering the spatial and time dependencies between the key components or parameters of the said management system. An example of such system may be a group of UAVs.

Keywords: structural model, information management systems, Petri-net, unmanned aerial vehicle (UAV)

\section{BUDOWA DYNAMICZNYCH MODELI STRUKTURALNYCH INFORMACYJNYCH SYSTEMÓW ZARZĄDZANIA PORUSZAJĄCYMI SIĘ OBIEKTAMI}

Streszczenie. W pracy autorzy próbuja znaleźć najlepszy sposób zaprojektowania dynamicznego modelu strukturalnego systemu zarządzania informacji poruszajacych się obiektów. Ten model strukturalny umożliwia organizowanie różnych systemów zarzadzania poruszajacych sie obiektów, biorac pod uwage przestrzenne i czasowe zależności pomiędzy kluczowymi komponentami lub parametrów tego systemu zarządzania. Przykładem takiego systemu może być grupa bezzałogowych statków powietrznych.

Keywords: model strukturalny, systemy zarządzania informacją, Petri-net, bezzałogowe statki powietrzne

\section{Introduction}

The structural models allow describing properties of the objects of any type. Based on the understanding of the structure of these objects, one can get an idea about it and separate the required parameters. In this case, they represent the following: integral characteristic, which integrates the whole object to the maximum extent; a parameter, which describes the spatial or time representation of the object; and the functioning process of an object taken as a whole.

Depending on the characteristics of the object, a description of its structure can be introduced in different forms.

\section{Problem analysis}

The organization of an information system, in which one component is a moving object $(R O)$, having features, namely: spatial distribution of its components; mobility of individual system elements in space and in the process of its functioning; the existence of critical parameters, which have their own specific interpretation, directly linked to the entire system functioning process.

Spatial distribution is determined by the necessity to create an object structure, which would bring spatially distributed components together in one system. This feature is shown in physical objects, having complex structure. In this case, a graphic display of the corresponding structure is used in the form of classic graphs. Thus, the minimum information load of such interpretation structure includes nodes of a graph $e_{i} \in E$, which identify the uniting elements and links between the nodes $v_{i j} \in V$, which identify the existence of the link between the individual elements $e_{i}$ and $e_{j}$.

Maximum information load of such interpretation structure lies in the fact that the links orientation is added to a minimum load in the form of arrows between the nodes, which is technically described as $e_{i} \rightarrow e_{j}$, and the introduction of a link weight concept, which by some means or other determines the significance of a certain link, which is written as following: as $v_{i j}\left(u_{i}\right)$ where $u_{i}$ is the link weight $v_{i j}$ between $e_{i}$ and $e_{j}$ nodes $[1,2,6]$. Such means are largely used for statistic structures, therewith the structure is considered statistic in terms of stiffness of physical cross-linking between the individual elements. This means that the directed lines, connecting individual components of the object, are characterized by weights, the amount of which is defined on bounded intervals, and physics of corresponding system functioning determines the possibility of changes in relevant intervals. For example, if there is a number of power objects, which are spatially distributed and are not mobile within the space of such distribution, the links between them, for instance, in form of electrical lines, are described by the structure graphic elements, which are the edges of graph $u_{i j}$, whereas a relevant line length is used as an edge weight. In this case, the line length $u_{i}$ is defined within a closed interval, where the lower limit corresponds to the minimum distance and the upper limit corresponds to the maximum distance between stations.

\section{Problem solving}

Function expansion of structural models, which consists of expanding the functional interpretation of nodes, in general can be introduced by Petri net [8]. It provides an analysis of the interaction of separate information flows, which in their interpretation are narrowed down to their designation in the form of signals. This interaction lies in synchronization of signals, which enter the node from different edges $v_{i k}$ and $v_{j k}$, which are included into the node $e_{k}$ and may come out from the node $e_{k}$ through the edges $v_{k g}$; signal delay in the node $e_{i}$ for some time $\tau_{i}$, before such signal can come out from the node $e_{i}$ through the edge $v_{i j}$; performing logical operations in the node $e_{i}$, which in realization of conjunction $\&$ or disjunction $V$ of two or more signals, which enter the node $e_{i}$. Moreover, the logical interpretation of signals can be determined by their absence or presence in the relevant nodes of Petri graph.

The expansion of the possibilities of graph means through their complication does not seem correct, since in this case the appropriate means stop corresponding to the core of structural means, which primarily provides simplicity and display of an object as a single set of different components.

In the case of distributed dynamic system, which is the information management system $R O$, which will be denoted as IUS, in order to introduce general structural descriptions, one must use at least those parameters, reflecting the spatial and time dependencies between the key components or parameters, which identify them at the required high level. 
Considering that in dynamic system we talk about the time interdependencies, thus time parameter can be taken as integral parameter, each value of which identifies a specific condition of individual components, which, in general, exist within the system and define it. The parameters, describing changes, which occur in the system, can illustrate examples of such parameters. Furthermore, since the dynamic characteristic of the system is linked to the changes within it, then the following integral parameters, except the time, can be other unspecified parameters, identifying the relevant changes within the system. Such parameters can be exemplified by parameters, describing changes of spatial coordinates, which determine the location of object individual components and other parameters related to it.

The classic method for describing time or dynamic dependencies lies in the use of graphs in the form of certain net. In order to describe some dynamic system structure, it is necessary to resolve a task of graph structure or net structure synthesis.

Classic oriented loaded graph is formally described by the following formula:

$$
G=F[f(V, E), U]
$$

where $f(V, E)$ describes edges orientation, which is given by the sequence of two nodes, assigned to one edge and is described by the formula: $f\left(v_{i}\right)=\left(e_{i j}, e_{k m}\right)$.

Often a functional relation $f(V, E)$ is depicted in an explicit form as a description of some multitudes of node pairs:

$$
f(V, E)=\left\{v_{1}\left(e_{1,1}, e_{12}\right), \ldots, v_{n}\left(e_{n, 1}, e_{n 2}\right)\right\} .
$$

This functional relation can be depicted in the form of one or some multitudes of simply ordered set, defined on the structure of $G$ graph, in which common edges are absent. That can be written as a formula:

$$
\begin{gathered}
f(V, E)=\left\{\omega_{1}\left[v_{11}\left(e_{1,1}, e_{12}\right), \ldots, v_{1 n}\left(e_{n, 1}, e_{n 2}\right)\right], \ldots,\right. \\
\left.\omega_{n}\left[v_{n 1}\left(e_{1,1}, e_{12}\right), \ldots, v_{n n}\left(e_{n, 1}, e_{n 2}\right)\right]\right\}
\end{gathered}
$$

where $\omega_{i}\left[v_{i 1}\left(e_{i, 1}, e_{i 2}\right), \ldots, v_{i+j}\left(e_{(i+j), 1}, e_{(i+j), 2}\right)\right]$ is a separate simply ordered set, which exists within the structure of $G$ graph. If the condition of the absence of common edges in simply ordered sets is met, the formula (2) can be written as follows:

$$
\begin{gathered}
f(V, E)=\forall \omega_{i} \forall v_{i j} \neg \exists v_{i j}\left\{\omega _ { 1 } \left[v_{11}\left(e_{1,1}, e_{12}\right), \ldots,\right.\right. \\
\left.\left.v_{1 n}\left(e_{n, 1}, e_{n 2}\right)\right], \ldots, \omega_{n}\left[v_{n 1}\left(e_{1,1}, e_{12}\right), \ldots, v_{n n}\left(e_{n, 1}, e_{n 2}\right)\right]\right\} .
\end{gathered}
$$

In order to describe time dependencies in a system, as already mentioned, the nets [7] are used in the form of graph structures. A particular feature of such graphs is their time ordering. Formally, the graphs, reflecting the nets, are described by the following formula and are called nets:

$$
D=\Phi(G, T)
$$

where $G$ is a graph with formula (1), and $T$ is parameter, according to which method of ordering, defined by a multitude $f(V, E)$, is realised. Such ordering is defined on the level of edges and is formally written as a following formula:

$$
D=\Phi\{F[f(V, E), U(T)]\}
$$

where $U(T)$ is functional relation, which defines the ordering in $G$ graph. If the ordering is considered as synchronization of events, which create the process of object functioning, the structural model (4) degenerates into a Petri graph. Within the considered IUS, the ordering is understood in the broader sense of the term. For example, let us assume that time, which value is measured according to some functional relation $y=\varphi(t)$, which in order to simplify the model can be linear function, or $y=a t+b$, is chosen as the $T$ parameter.
A synchronization of the functioning process is an example of a situation, where the functional parameter, which determines the fact of one specific event or a chain of events, is used as the $T$ parameter. In this case, the ordering in the dynamic structure of the object is determined by the identification of occurrence of events and logical analysis, defining the conditions of system transition to the next state. In this case, the functioning process within the structural model is described as a time-varying function with the ordinary moment $t_{0}$, which corresponds to the beginning of functioning process and the finishing moment $t_{n}$, corresponding to the completion of functioning process or the completion of the separate cycle of functioning process.

Implicitly the dynamic structural model is described by the formula (4). In order to be able to introduce this model explicitly or in another constructive form, we shall consider several features of IUS system. Since the structural model is most common, compared to the models of individual components, it should reflect all the requirements, imposed to the IUS system in general. It must be noted that the reflection and provision of functioning dynamics to reduce to synchronization processes are not sufficient for the following reasons: the synchronization process makes it possible to continue the functioning only if all required events have occurred in the system till the specified moment; a key parameter of the synchronization process is time parameter, which represents the moment in which the object fluidity is tested when it comes to the functioning process in realtime mode; mainly the task of fluid value of time in the form of linear function corresponds to the most common interpretation of this parameter, which does not depend on the characteristics of the object of management.

In the case of $R O$ management system of the UAV type, IUS functioning must continue irrespective of whether all identified events are carried out in the system or not $[3,4,5]$. This means that IUS functioning process of UAV must be divided and shall continue by some means or other depending on its fluidity. In order to arrange this, the possibility to change the key fluid parameter of dynamics control to another parameter has to be foreseen. For example, the time parameter is replaced by liveness parameter, or another parameter, which is determined based on the analysis of IUS fluidity. If it is impossible to select the dynamic parameter in the functioning process, in order replace the fluid parameter, a modification of task objective is done; the task is further resolved in such a manner, which makes it possible to determine the new dynamic parameter. As a part of this approach, it is vital to solve the task of synthesis of the static component of the $G$ structural model with a dynamic component of the structural model, which will enable to get a synthesized dynamic structural model $D$. As mentioned above, the static structural model is described by the direct marked graph:

$$
G=F[f(V, E), U],
$$

where $U$ is a multitude of graph labeling, which can lie in the nodes or edges labeling. The functioning process can be introduced in the following ways.

It is possible to draw a maximal graph, describing all possible situations, which may occur in the process of system management, for example, UAV. In this case, such graph is described by a following formula:

$$
G^{\max }=G_{1} \cup G_{2} \cup \ldots \cup G_{n},
$$

where $G_{i}$ is a separate expansion. Within the structural model the following tasks, which have interpretation in the IUS, can be resolved:

- A task of reaching selected nodes,

- A task of structural model core allocation,

- A task of constructing isomorphic structure within the structural model and a number of other tasks.

A statistic structure in a structural model $(M S)$ is a multitude of all evens, which are generated in the IUS, while resolving the management tasks, which join together by their edges, defining 
their dependencies and orientation in the MS. If resolving one class of tasks is implemented by several options of their resolving implementation, such graph grows from the simply ordered set $\omega_{i}$ into some structure. Therefore, the statistic structural model $(S M S)$ is a description of all possible processes and their fragments. The dynamic structural model only includes the components, which participate in the fluid process.

The second method of $M S$ structural introduction for the IUS of UAVs lies in the implementation of graph structure, reflecting the basic graph system. The expansion of such a structure is done in the process of implementing various types of IUS functioning, which are defined by the objective of a task to be solved, and the conditions to be met during its resolving. Since the functioning processes are considered within the $M S$ model at the structural level, the mechanisms for the $M S$ core expansion can be based not only on graph extension methods, but methods of logical means of transformations.

Generally, the $M S$ is divided into active and passive components. The degree of passivity is determined by the number of structure fragments initiations $m s_{i} \in M S$, which are defined for a given period of the IUS functioning, which is defined as follows: $\Delta t_{i}=t_{i j}-t_{i(j-1)}$. Thus, the value $\Delta t_{i}$ is formed in each case, and depends on the requirements, complementing the description of the task objective to be resolved.

Let us assume that the structure $G(V, E, U)$ is a static substructure or a static fragment of $M S$. $M S$ dynamic expansion or structure $G(V, E, U)$ is a certain set of rules, which provides the construction of new simply ordered set in the structure $G(V, E, U)$. Now let us consider the definition of fluid expansion $M S$ by a dynamic component.

Definitions 1. The dynamic expansion of the structure $G(V, E) \subset M S$ is a multitude of simply ordered sets, generated by the system:

$$
\begin{gathered}
L\left(L_{1}, \ldots, L_{m}\right) \& L_{i}\left(y_{i 1}, \ldots, y_{i n}\right) \& \\
{\left[y\left(y_{1}, \ldots, y_{k}\right) \Rightarrow[E \subset G(V, E, U)],\right.} \\
\forall\left(y_{i j} \in y\right)\left\{P\left[y_{i}\left(u_{i}\right) \Rightarrow D\right]\right\}, \\
\forall y_{i j}\left(y_{i j}\left(u_{i}\right) \rightarrow\left[e_{i}^{*}\left(u_{i}^{*}\right) \cup G(V, E, U)\right],\right.
\end{gathered}
$$

where $y_{i j}$ are logical variables, which have interpretation in the dyadic multitude $d, \Rightarrow$ is a symbol, which in this case is used to describe the fact that the left side allows the interpretation in the components of the right side, $y_{i j}\left(u_{i}\right) \rightarrow e_{i}^{*}$ is an output of variables $y_{i j}$ of a new node in $G(V, E, U)$, graph, which has a common edge with the node, which weight or index is $u_{i}$.

Definitions 2. The dynamic element of $M S$ model is a fragment $g_{i}$, which is generated by the rule of derivation system $L\left(L_{1}, \ldots, L_{m}\right)$ and is a separate simply ordered set $\omega_{i} \in W_{i}$, having common nodes $e_{i}^{*}$ in $G$, and also may have common nodes $e_{i}^{*}\left(e_{j}\right)$ with $G_{i}$ or $e_{i}^{*} \equiv e_{j}$.
The dynamic expansion $D_{i}\left(\omega_{i 1}, \ldots, \omega_{i 2}\right)$ of closed form is some fragments of graphic structure $G(V, E, U)$. Accordingly, such expansions should not lead to the appearance of anomalies within the full model structure, such as occurrence of deadlock vertexes, process looping, initiated in $G=D(V, E, U, L)$ and a number of other anomalies typical for graph structures and, thus, the structural models.

\section{Conclusion}

The dynamic expansion of $M S$ structural model of the IUS system can be implemented in the following ways:

- in the process of setting the IUS to solve some task;

- in the process of task solving, which involves the maintenance of a process in real-time mode;

- in the case of occurrence in IUS space in the process of resolving a particular task, of a specific anomaly, which is interpreted as a certain indeterminateness.

\section{References}

[1] Busacker R.G., Saaty T.L.: Finite Graphs and Networks: An Introduction with Applications/ Published by McGraw-Hill Book Company, Inc., 1965

[2] Harary F.: Graph theory. M.: Mir, 1973

[3] Korobchinskiy M.V.: Analyzing a method of modeling relations between individual components of information system The National Academy of Sciences of Ukraine, Issue 65, 2012, p. 174-182.

[4] Korobchinskiy M.V.: Analyzing the possibilities of mathematical logic means to identify the anomalies in control system of the UAV of UAV, The National Academy of Sciences of Ukraine, Issue 65, 2012, p. 165-172.

[5] Korobchinskiy M.V.: Topical issues of organization of the UAV's team flights control, Collected volume of scientific works of G.E.Pukhov Institute of modeling issues in power industry. The National Academy of Sciences of Ukraine, Issue. 61, 2011, p. 14-25.

[6] Yevstigneyev V.A.: Application of graph theory and programming. M.: Nauka, 1985.

[7] Yemelichev V.A., Melnikov O.I., Sarvanov V.I., Tyshkevitch R.I.: Lectures on graph theory, M.: Nauka, 1990.

[8] Zambitskiy D.K., Lozovanu D.D.: Algorithms and resolving optimization tasks in the networks. Kishinev: Shtiitsa, 1983.

Ph.D. Maksym Korobchynskyi

e-mail: maks_kor@ukr.net

Associate Professor, Ph.D. (technical sciences), presented a thesis in 2006 titled "Design Methods for the UAV-Based Communications Systems". Research interest: complex dynamic systems modeling.

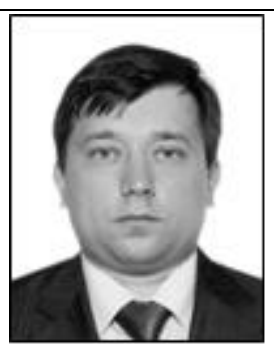

\section{Prof. Oleg Mashkov}

e-mail: mashkov_oleg_52@mail.ru

Professor, Doctor of Technical Sciences, Honored Leader in Science and Technology, Academician of the Aerospace Academy of Sciences. Vice-rector for Scientific Work at State Ecological Academy for postgraduate education and management. Research interest: modeling and research of the stable movement and navigation control systems.

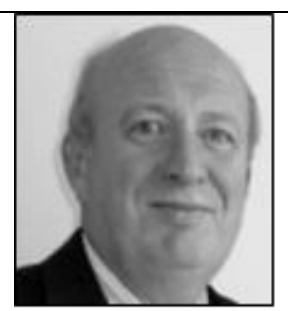

